\title{
Forms and Methods of State Regulation of the Economy in the Context of the Implementation by the Russian Federation of Measures to Combat the Spread of New Coronavirus Infection (COVID-19)
}

\author{
Vladimir M. Redkous
}

Sector of Administrative Law and Administrative Process, Institute of the State and Law, Russian Academy of Science; Academy of the MIA of Russia, Moscow, Russia,

Corresponding author. Email: rwmmos@ rambler.ru

\begin{abstract}
The relevance of the work is due to the needs of improving state regulation in the economic sphere and its administrative and legal support, the applied forms and methods in the face of crisis phenomena caused by the spread of a new coronavirus infection (COVID-19). The article provides an analysis of the forms and methods of state regulation used in the Russian Federation in the context of the spread of the new coronavirus infection (COVID-19), aimed at supporting citizens and the economy; substantiated the functioning of the administrative-legal regime of sanitary and epidemiological welfare of the population.

Keywords: public administration; state regulation; area of the housekeeper; executive branch; National security; medical safety; sanitary and epidemiological welfare of the population; forms of government; public administration methods; governmental support; administrative and legal regimes
\end{abstract}

\section{INTRODUCTION}

The whole world is faced with the spread of a new coronavirus infection (COVID-19), which not only threatens life and human health, but also negatively affects the economy of the Russian Federation. The most important task is to minimize this negative impact, to reduce the inevitable socio-economic losses. Therefore, along with measures aimed at preventing the disease, increasing the opportunities for healthcare, decisions are being made to support Russian families, employment and incomes of citizens, to promote individual entrepreneurs, small and medium-sized businesses, and system-forming companies.

The coronavirus epidemic has most negatively affected and continues to affect business and entrepreneurial activity, the dynamics of the labor market. This is due to the violation of many economic, cooperative, trade relations. Due to the necessary restrictive measures, many enterprises were forced to change their usual work schedule. The situation is especially acute for small and medium-sized businesses, for organizations in the service sector. Demand fell sharply; retail sales in Russia in April 2020 decreased by more than 35 percent [1]. Energy consumption dropped sharply. The volume of lending to the real sector of the economy decreased, which led to the suspension of many investment programs, development plans and enterprise renewals.

In these conditions, the role of the state, the public administration system in regulating economic processes, as well as the role of legal support for functioning in the economic sphere as the most important sphere of public administration, is growing. The implementation of decisions to support citizens, the economy, business, and small and medium-sized enterprises largely depends on this. It is necessary to continue to develop new, additional steps that are adequate to the level of new challenges, use all resources, tools, reserves for an active anti-crisis policy, use them as efficiently and with tangible results as possible for the economy and citizens. The solution to these problems is possible with the effective use of forms and methods of public administration of the economic sphere.

\section{MATERIALS AND METHODS}

The study of forms and methods of state regulation in the economy in the context of the implementation by the Russian Federation of measures to combat the spread of new coronavirus infection (COVID-19) involves the use of various research methods, the main of which are 
dialectic, formal logical, analysis and synthesis, functional. State regulation is considered as the most important function of public administration, which makes it possible to consider the functions of state regulation in the context of public administration functions. The conclusions are based on the results of scientific research by domestic administrative scientists (Yu.S. Adushkina, Z.A. Bagishaev, B.N. Gabrichidze, D.N. Bahrakh, M.I. Eropkin, Yu.M. Kozlov, A.E. Luneva, V. M. Manokhina, Yu.N. Starilova, D. M. Ovsyanko, N. F. Popova, I. D. Fialkovskaya and a number of other scientists) [2] who developed the author's approaches to the determination of forms and methods public administration on the basis of general, basic ideas about the form of public administration as an external expression of the controlling influence of a subject of management on a controlled volume so to achieve the goals and objectives of management, and a method of governance as a set of management methods and techniques of influence, performing administrative functions. These scientists basically do not object to dividing the functions of public administration into legal and non-legal, and methods into administrative and economic, persuasion and coercion, which is acceptable when considering state regulation in the field of economics.

Forms and methods of public administration are implemented in all spheres of life, including in the field of economics [3]. From a legal point of view, it is rather difficult to choose a term that uniquely defines the role of the state and public administration in the regulation of the economy. The starting point will be the recognition that, despite the market relations that make up the basis of the economy, freedom of contract, competition, and the existence of economic mechanisms of self-regulation, the state remains the most important entity that fulfills its mission and functions in the field of economy. Modern forms of state regulation of economic relations are clearly and easily identified by Yu.A. Tikhomirov [4], speaking about the general regulatory regulation of the economy; software-installation, legalizing, normative-quantitative and high-quality, control and forbidden ways of regulating the economy, as well as means of maintaining and stimulating the activities of business entities. Modern methods of direct and indirect (economic) administrative and legal regulation of the economy are disclosed in sufficient detail in the works of A.F. Nozdrachev [5].

The regulatory role of the state in the economy increases during periods of economic crisis, the onset of other unfavorable moments in the development of the state and society, requiring the mobilization of all resources to solve problems. This concerns responding to threats to national security, which should be recognized as the spread of a new coronavirus infection (COVID-19).

In the theory of administrative law it is justified, and it has been proved by the practice of public administration that administrative and legal regimes act to ensure the mobilization of the resources of the state and society in order to solve problems as one of the most acceptable organizational and legal forms [6], which makes it possible to justify the functioning of administrative the legal regime of sanitary and epidemiological welfare of the population.

\section{RESULTS}

1. The spread of a new coronavirus infection (COVID-19) has a negative impact not only on people's lives and health, but also on the economy, causing a decrease in business, entrepreneurial, financial and investment activity, a deformation of the labor market, a decrease in energy consumption, and retail trade, and also other negative consequences, which predetermined the immediate reaction of the state in order to prevent negative consequences.

2. The spread of a new coronavirus infection is not only a threat to medical safety and a threat to the sanitary and epidemiological well-being of the population, but it also poses a threat to economic, food, migration and other types of national security, which requires a prompt and comprehensive response to its occurrence and distribution in order to prevent and localize adverse consequences for various areas of public life and state activity.

3. The forms and methods of state management of the economy in the context of the spread of a new coronavirus infection have acquired content that corresponds to the nature of the threats to the country's economic development. The main role still belongs to legal forms of government, in particular legal acts issued by the President of the Russian Federation and the Government of the Russian Federation, acts of federal executive bodies and executive bodies of the constituent entities of the Russian Federation, acts of executive bodies of local selfgovernment. Without changing the substantive part of the main institutions of legal regulation of the economy, these acts correct the procedural aspects of their implementation, reducing the likelihood of adverse consequences for both producers of economic products and its consumers. This shows the efficiency and flexibility of executive and administrative activities of the executive branch of the Russian Federation.

4. In the context of the spread of the new coronavirus infection, the role of persuasion as the most important method of public administration has intensified, which is manifested in the impact on the consciousness of all participants in economic relations to voluntarily and faithfully observe the restrictions imposed on the time of counteraction to the new coronavirus infection. Failure to comply with established requirements and prohibitions entails the use of administrative coercive measures, including administrative liability. We should also talk about the growing importance of economic methods of state influence on the economy in order to reduce or partially compensate for the amount of damage suffered by economic entities. 
5. In the context of the spread of the new coronavirus infection (COVID-19), it is legitimate to talk about the effect of the administrative-legal regime for ensuring the sanitary and epidemiological well-being of the population.

\section{DISCUSSION}

The issues of the modern development of law and the economy in their unity and contradictions, caused by the action of various factors of an objective and subjective nature, have become the subject of close study of scholars of various branches of legal science, including administrative law. The economic sphere is the basis for the functioning of the state, the exercise of the rights and freedoms of citizens, a prerequisite for the construction and development of modern civil society [7].

The diversity and dynamics of economic relations, a large number of subjects of economic activity, the diversity of their interests, the need to satisfy both the public law needs of the development of the state and society, and the private law interests of individual and collective subjects of economic activity require the use of all forms of management established in law and solving emerging issues to achieve a common socially significant goal, which in the most concentrated form it is defined in the definition of "national security", enshrined in the National Security Strategy of the Russian Federation of December 31, 2015 [8].

In modern administrative law, the concept characterizing the impact of administrative law on the economy has not yet been established; various combinations of words are used: on the one hand, "legal"; on the other hand "management", "regulation", "impact"; with the third "area of the economy", "area of the economy", "area of economic development", etc. We are talking about the administrative and legal impact on the economy [9], legal administration in the economy [10], state administration of the economy [11], state administration in the economic sphere [12], state participation in the economy, and others. Differences in the use of concepts reflect the views of the authors on the degree of state influence on the economy, on the economic processes occurring in it. Without going into a discussion on this issue that deserves a separate study, we note that as long as the state exists, it will influence the economic sphere by all available means, and, above all, legal, in order to achieve stable progressive economic development. In the economic sphere, such basic functions of law as regulatory, protective and educational will be manifested, allowing the state not to give up the economic sphere to the mechanisms of economic self-regulation, but to seek its development by certain forms and methods. The scope of the economy gave a definition of a set of public administration methods that are not related to direct state influence on the subject of law in the field of economic relations, which are called economic. These methods, along with administrative ones, have been successfully used, including by government entities, to achieve the goals of public administration both in the economic sphere as a whole and in its individual areas [13].

The role of the state in regulating the sphere of the economy intensifies during periods of the onset of the socalled special, emergency, crisis circumstances. Currently, both for Russia and for most foreign countries, this circumstance is the distribution of COVID-19. This period for the Russian economy is one of the periods of the highest strength tests, since negative trends are developing in parallel with sharp fluctuations in the global oil price market, as well as with ongoing economic sanctions against the Russian Federation by Western states.

Therefore, not only the development of the Russian economy in the crisis and post-crisis period, but also the solution of the whole complex of tasks facing the Russian state at the present stage of its development will depend on the proper selection by the authorized state bodies of the forms and methods of state regulation in the economy. Forms and methods of public administration are used as part of the administrative and legal impact on the economy, as part of its administrative and legal regulation. The combination of direct and indirect effects on the economy, administrative and economic methods characterizes the degree of state influence on the economy in a given period of development of the state and society. In relation to the sphere of economy, the state should perform several basic functions, in particular: the formation of a regulatory framework conducive to the smooth functioning of market mechanisms; protection of competition as the basis of a market-oriented economy; redistribution of income for social purposes; adjustment of resource use; stabilization of the economy (exercising control with the level of employment, inflation), stimulating economic growth and a number of others [14]. The role of administrative law is high in the implementation of these functions.

To determine what specific forms and methods of public administration in the economy are most in demand during the spread of a new coronavirus infection, the experience of administrative regulation in a specified period of time should be considered. Immediately, we note that the spread of a new coronavirus infection should be associated with the action of threats to medical safety, threats to the sanitary and epidemiological well-being of the population. Under a certain set of circumstances, the development of threats to medical security can turn into a threat to state security, therefore, a set of measures is being taken to prevent the spread of a new coronavirus infection at all levels of state and municipal government. Practice shows that the action of this threat to medical security simultaneously raises threats to other types of national security, primarily economic, migration, food, and even international, as tensions have arisen between a number of leading world states (for example, the USA and China) in connection with the spread of new coronavirus infection. These circumstances leave an imprint on the content and direction of decisions taken in the field of 
counteracting the spread of COVID-19 on the forms and methods of state management of the economy used in connection with these.

In the context of the spread of COVID-19, the most important form of state management of the economy becomes the general regulatory regulation of the economy. The amendments to the Russian legislation made it possible to quickly enforce measures aimed at supporting citizens and the country's economy in by-laws of steam regulations. A major role in this is assigned to the by-laws of the President and the Government of the Russian Federation. By their nature and content, these measures correspond to the features of administrative legal regimes highlighted in the science of administrative law [15].

The contents of the Decree of the President of Russia dated April 2, 2020 No. 239 (hereinafter referred to as Decree No. 239) containing a list of measures aimed at ensuring sanitary and epidemiological welfare of the population in the Russian Federation in connection with the spread of COVID-19 are considered.

The direction of the measures taken to solve the most significant tasks of management and legal regulation in the field of ensuring the sanitary and epidemiological well-being of the population is indisputable. There is a specific specific socially significant goal of the same name, closely associated with ensuring medical security, as well as other types of national security, for the achievement of which an administrative-legal regime is being established. The situation that develops in a certain region as a whole throughout the country is taken into account when the regime is introduced. The text of Decree No. 239 talks about the introduction of security measures ("restrictive and other measures") based on the sanitaryepidemiological situation and the distribution of COVID19 in the constituent entity of the Russian Federation, which also indicates the compulsion of the measures taken.

Each administrative and legal regime is characterized by the establishment of rules of conduct for citizens, the rules of activity of organizations and other subjects of law, the introduction of additional duties that may be of a special nature. On the basis of Decree No. 239 in the relevant territory, in conjunction with the distribution of COVID19 , it is possible to establish a special procedure for the movement of persons and vehicles, with the exception of vehicles engaged in inter-regional transportation [16], the activities of individual entrepreneurs are suspended (limited) and also individual organizations, regardless of legal form and form of ownership. At the same time, the possibility of the onset of conditions for the introduction of a high alert mode, an emergency situation with the introduction of the rules of behavior binding on citizens and organizations by the Government of Russia [17] is not excluded.

The development and implementation of restrictive and other measures is entrusted to the relevant entities - senior officials (heads of the highest executive bodies of state power) of the constituent entities of the Russian Federation. It is only natural that they will also be liable for failure to comply with the provisions of Decree No. 239.

The effectiveness of restrictive and other measures will be achieved only with the full and systematic use of all legal means of influence contained not only in Decree No. 239, but also in other regulatory legal acts, coordination of activities and interaction of all authorized and interested bodies and organizations, establishment of additional guarantees of compliance the rights and legitimate interests of all entities, establishing control and supervision over the implementation of these measures, as well as legal liability measures.

According to the author, in the context of the spread of a new coronavirus infection, it is legitimate to talk about the introduction of an administrative-legal regime of sanitary and epidemiological welfare of the population as an established procedure for regulating the activities of state bodies and non-governmental organizations, their officials, citizens' behavior aimed at clearly regulating public relations in the field of sanitary -the epidemiological well-being of the population, providing for the possibility of implementing the complex will limit effective and other measures, other regulatory measures, the nature of which is determined by the need to ensure the state of public health, the human environment, in which there is no harmful effect of environmental factors on the person and favorable conditions for his life (sanitary and epidemiological well-being of the population) are ensured. The concept of sanitary and epidemiological welfare of the population was used in the development of this definition, normatively enshrined in the Federal Law of March 30, 1999 No. 52-FZ "On the Sanitary and Epidemiological Welfare of the Population" [18].

The action of the aforementioned administrative and legal regime extends to the sphere of economic relations and economic activity. In the field of economics, the Government of the Russian Federation is actively exercising the powers granted to it by the Constitution of the Russian Federation, Federal Constitutional Law of December 17, 1997 2-FKZ "On the Government of the Russian Federation" [19] and other normative acts.

The Russian government has developed and approved a number of measures to ensure sustainable economic development [20]. Thus, specific measures of support to economic entities (organizations and individual entrepreneurs) that are engaged in those areas of activity that have deteriorated to the greatest degree due to the deterioration of the situation caused by the spread of COVID-19 have been identified. These measures relate to the extension of the deadlines for the payment of a number of taxes (advance payments) established by the legislation on taxes and fees, insurance premiums, etc. It was decided to suspend for a certain time the adoption of decisions on certain types of field, repeated field tax audits, checks on the completeness of tax calculation and 
payment, checks on compliance with currency legislation, and a number of other measures. The procedure for granting deferment (installment plan) for the payment of taxes, advance payments of taxes and insurance contributions has been approved. Measures have been established that exclude the application of tax sanctions for a number of tax violations, the deadlines for sending a request for payment of taxes, fees, insurance premiums, interest, fines, interest and the decision to recover them have been increased.

A moratorium has been introduced on initiating bankruptcy cases at the request of creditors in relation to individual debtors; rules for providing subsidies to air transport organizations approved; incentives for small and medium-sized businesses to defer payments under federal property lease agreements have been established; financial resources are allocated for reimbursement of expenses to the established categories of participants in economic activity.

Important for the regulation of economic relations in crisis conditions of the spread of coronavirus was the approval of the list of sectors of the Russian economy that were most affected by the deterioration of the situation as a result of the spread of a new coronavirus infection [21].

The term of validity of licenses has also been extended (in particular, for the production and circulation of ethyl alcohol, alcoholic and alcohol-containing products, for subsoil use, for the provision of communication services, television and radio broadcasting, for private detective and security activities) and other permits (in particular on ship radio stations, as well as state registration of drugs), whose validity expires from March 15 to December 31, 2020 [22]. It has been proposed to conduct the corresponding on-site inspections using photo, audio and video fixation means, video conferencing, as well as remote monitoring means.

The features of the application of permitting regimes stipulated by the urban planning legislation of Russia, as well as legislation on accreditation in the national accreditation system, on the basics of protecting the health of citizens in the Russian Federation, on mineral resources, on education, on valuation activities in the Russian Federation, on the electric power industry, and on industrial safety hazardous production facilities, on the safety of hydraulic structures.

Financial resources for reimbursement of expenses incurred by tour operators are allocated by Orders of the Government of the Russian Federation.

All this testifies to the active use by authorized entities of state administration of all forms and methods of activity to respond to the crisis situation with the maximum use of those forms and methods that quickly and effectively solve problems.

\section{CONCLUSION}

The analysis showed that in order to counter the spread of the new coronavirus, taking into account the current situation, all forms of state regulation are used to the maximum extent.

The use of legal forms is associated with: general regulatory regulation of relations in the economic sphere; determination of the size and procedure for the provision of means of supporting and stimulating the activities of business entities (subsidies, loans, benefits); regulation of the features of the use of legalizing means of regulating the economy, primarily the implementation of licensing and permitting activities; the implementation of control and forbidden methods of regulating the economy in terms of conducting scheduled and unscheduled inspections, accounting measures, and the application of sanctions for committed offenses; determination of appropriate regulatory, quantitative and qualitative means of regulating the economy (quotas, standards, prices). Nonlegal forms provide for the adoption and execution of management decisions, thereby creating favorable conditions for the implementation of legal forms of government.

An analysis of the applied methods of state regulation in the sphere of economics shows a sharp increase in the role of economic management methods aimed at maintaining employment in the sphere of economics, compensating the subjects of economic relations for damages, and stimulating the resumption of production after the crisis. The role of persuasion as a regulatory method also increases sharply, ensuring that all subjects consciously fulfill restrictions in the context of counteracting the spread of coronavirus infection, which allows achieving a balance of interests of various participants in economic relations without applying state coercion measures.

\section{REFERENCES}

[1] Meeting on economic issues on April 14, 2020, Available at: http://www.kremlin.ru/events/president/news/63200.

[2] I.D. Fialkovskaya, Theoretical issues of the interaction of forms and methods of public administration, Bulletin of the Nizhny Novgorod University. N.I. Lobachevsky 6 (2010) 261-267.

[3] A.M. Abakirova, M.A. Abdyraev, G.A. Vasilevich, Modernization of administrative legislation (goals, objectives, principles and current trends), in: Institute of Legislation and Comparative Law under the Government of the Russian Federation, INFRA-M, 2019. 
[4] Yu.A. Tikhomirov, Legal regimes of state regulation of the economy, Law and Economics 5 (2000) 5 .

[5] A.F. Nozdrachev, The content of the institute of administrative and legal regulation of economic relations, in: Institutes of administrative law of Russia, Publishing house IGiP RAS, 1999, pp. 94-99.

[6] V.B. Rushailo, Administrative and legal regimes, monograph, Shield - M, 2000.

[7] A.M. Voronov, M.N. Kobzar-Frolova, V.M. Redkous, A.M. Gogolev, Civil society of modern Russia: problems of implementation of constitutional rights and freedoms, International Journal of Economics and Business Administration 7(1) (2019) 243-251.

[8] Decree of the President of the Russian Federation dated December 31, 2015, No 683 "On the National Security Strategy of the Russian Federation", Meeting of the legislation of the Russian Federation, 2016, No 1 (part II), Art. 212.

[9] Z.A. Saidov, Administrative impact on the economy, monograph, Unity-Dana: Law and Law, 2012.

[10] Legal administration in the economy, Actual problems, Yu.A. Tikhomirov (Ed.), Justice, 2018.

[11] Yu.A. Tikhomirov, V.P. Emelyantsev, A.A. Ayurova et al, Efficiency of legislation: theory and practice, Institute of Legislation and Comparative Law under the Government of the Russian Federation, INFRA, 2015.

[12] A.N. Sokolov, Municipal Law and Public Administration in Russia, Yurkompani, 2016.

[13] M.N. Kobzar'-Frolova, V.A. Frolov, Administrative-legal forms and methods for regulation of economic activity of customs bodies, The topical issues of public law 1(25) (2014) 56-63.

[14] K.R. McConnell, S.L. Bru, Economics: Principles, problems and politics 1 (1995) 94.

[15] V.M. Redkous, The concept of administrative legal regimes established in the field of ensuring national security, Law and State: Theory and Practice 12(60) (2009) 92-95.

[16] Decree of the President of the Russian Federation of April 2, 2020, No 239 'On measures to ensure sanitary and epidemiological welfare of the population in the Russian Federation in connection with the spread of a new coronavirus infection (COVID-19)", Collection of legislation of the Russian Federation, 2020, No 14 (Part I), Art. 2082.

[17] Decree of the Government of the Russian Federation of April 2, 2020, No 417 “On the approval of the Rules of Conduct binding on citizens and organizations when introducing a high alert or emergency", Official Internet portal of legal information, Available at: http: // www. pravo.gov.ru 04/03/2020.

[18] Federal law of March 30, 1999, No. 52 "On the sanitary-epidemiological well-being of the population", Collection of laws of the Russian Federation, 1999, No 14, Art. 1650.

[19] Federal constitutional law of December 17, 1997, No 2-FKZ "On the Government of the Russian Federation", Collection of legislation of the Russian Federation, 1997, No 51, Art. 5712.

[20] Decree of the Government of the Russian Federation of April 2, 2020, No 409 "On measures to ensure the sustainable development of the economy", Official Internet portal of legal information, Available at: http://www.pravo.gov.ru.

[21] Decree of the Government of the Russian Federation of April 3, 2020, No 434 "On approving the list of sectors of the Russian economy that were most affected by the deteriorating situation as a result of the spread of a new coronavirus infection", Official Internet portal of legal information, Available at: http://www .pravo.gov.ru.

[22] Decree of the Government of the Russian Federation of April 3, 2020, No 440 "On the extension of permits and other features in relation to licensing activities in 2020", Official Internet portal of legal information, Available at: http://www.pravo.gov.ru04/23/2020. 